\title{
Critical evaluation of latanoprostene bunod in the treatment of glaucoma
}

This article was published in the following Dove Press journal:

Clinical Ophthalmology

18 October 2016

Number of times this article has been viewed

\author{
Giancarlo A Garcia \\ Philip Ngai \\ Sameh Mosaed \\ Ken Y Lin
}

Department of Ophthalmology, Gavin Herbert Eye Institute, University of

California, Irvine, Irvine, CA, USA
Correspondence: Ken Y Lin Department of Ophthalmology, Gavin Herbert Eye Institute, University of California, Irvine, 850 Health Sciences Road, Irvine, CA 92697-4375, USA Email klin@post.harvard.edu

\begin{abstract}
Latanoprostene bunod (LBN) is a novel nitric oxide-donating prostaglandin $\mathrm{F}_{2 \alpha}$ receptor agonist in clinical development for intraocular pressure lowering in open-angle glaucoma and ocular hypertension. Currently in Phase III clinical trials in the USA, European Union, and Japan, LBN has demonstrated promising efficacy while maintaining safety and tolerability. We review preclinical and clinical developmental efforts and evaluate the potential role of LBN monotherapy in the management of open-angle glaucoma and ocular hypertension. The current LBN clinical development program comprises eight trials, four of which have resulted in publication of complete methodology and outcomes. We additionally pool adverse events data to determine incidences across three pivotal studies. Evidence thus far indicates that LBN may be a safe and effective ocular hypotensive agent, although the potential neuroprotective effects and the impact on visual field loss remain to be evaluated.
\end{abstract}

Keywords: uveoscleral outflow, glaucoma medical treatment, ocular hypertension, latanoprostene bunod, nitric oxide, clinical trial

\section{Introduction}

Glaucoma, the second leading cause of blindness worldwide, is characterized by permanent visual field loss from apoptosis and atrophy of retinal ganglion cells. Intraocular pressure (IOP) plays a pivotal role in the pathogenesis of glaucoma, although recent evidence has also implicated pressure-independent etiologies. ${ }^{1,2}$ However, IOP is currently the only modifiable risk factor, and its lowering remains the objective of most current medical and surgical management. Visual disability from glaucoma is preventable with timely and effective treatment. In the management of open-angle glaucoma (OAG) and ocular hypertension (OHTN), topical ocular antihypertensive medications are the most commonly used initial therapy. Of these, prostaglandin analogs (PGAs) such as latanoprost (Xalatan ${ }^{\circledR}$; Pfizer, Inc., New York, NY, USA) are the preferred first-line medication.

PGAs have demonstrated enhanced efficacy, safety, and tolerability compared to other classes of topical ocular antihypertensives and can significantly forestall disease progression. ${ }^{3}$ In addition, the once-daily regimen is associated with improved compliance compared to more frequently dosed eye drops. ${ }^{4-7}$ Nonetheless, patient compliance with these medications is still a challenge, with adherence and persistence rates generally below $50 \% .{ }^{4,8}$ As such, the development of more potent medications without sacrificing safety, tolerability, and convenience of dosing - may be beneficial in optimizing patient outcomes.

Latanoprostene bunod (LBN: NicOx S.A., Sophia-Antipolis, France, and Bausch + Lomb, Rochester, New York, NY, USA; initially developed by Pfizer, Inc.) is a novel 
nitric oxide (NO)-donating PGA currently being investigated for use in the reduction of IOP in individuals with $\mathrm{OAG}$ and OHTN. LBN (also known as PF-03187207, BOL-303259-X, NCX-116, and Vesneo ${ }^{\mathrm{TM}}$ [Bausch + Lomb]) has demonstrated profound IOP lowering and favorable safety profile in clinical trials in humans.

We review the preclinical and clinical development programs for LBN as of June 2016 and discuss the potential role of $\mathrm{LBN}$ in the management of OAG and OHTN. Publications considered for inclusion in this analysis were selected in PubMed using the search terms "latanoprostene bunod", "PF-03187207”, "BOL-303259-X”, "NCX-116”, "Vesneo", "nitric oxide", "comparative study [publication type]", and "glaucoma/drug therapy*[MeSH]." Clinical studies were referenced with their respective listings on ClinicalTrials.gov. Identification of unindexed clinical trials was achieved using the search terms "latanoprostene bunod," "PF-03187207", "BOL-303259-X", and "NCX-116" in the

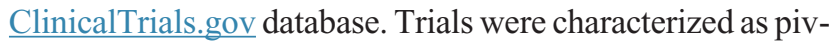
otal based on the strength of methodology and the availability of outcome data. To expand our search results and to review reports not currently indexed, we performed ad hoc searches using these search parameters for articles and abstracts from meetings of the following societies: Association for Research in Vision and Ophthalmology, American Academy of Ophthalmology, International Society for Eye Research, American Glaucoma Society, European Glaucoma Society, and World Glaucoma Congress.

\section{Pharmacology Mechanism of action}

The molecular structure of LBN is nearly identical to that of latanoprost (Figure 1). LBN is distinguished, however, by the integration of an NO-donating moiety (a terminal butyl nitrate ester functional group) in lieu of an isopropyl ester. The putative ocular hypotensive mechanisms of LBN are outlined in Figure 2. Upon topical administration at the ocular surface, LBN is hydrolyzed by endogenous corneal esterases into latanoprost acid - the active component of latanoprost - and butanediol mononitrate, which is further metabolized to NO and the inactive 1,4-butanediol. ${ }^{9}$

Primary open-angle glaucoma (POAG) and OHTN are associated with greater resistance to aqueous outflow through trabecular meshwork (TM) and Schlemm's canal (SC, conventional pathway), although the pathophysiology associated with this outflow dysfunction is not fully understood. ${ }^{10}$ Latanoprost is structurally similar to prostaglandin $\mathrm{F}_{2 \alpha}$ $\left(\mathrm{PGF}_{2 \alpha}\right.$; Figure 1) and acts as a selective $\mathrm{PGF}_{2 \alpha}$ receptor
A

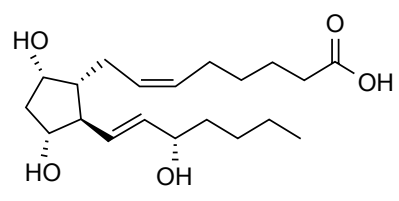

B
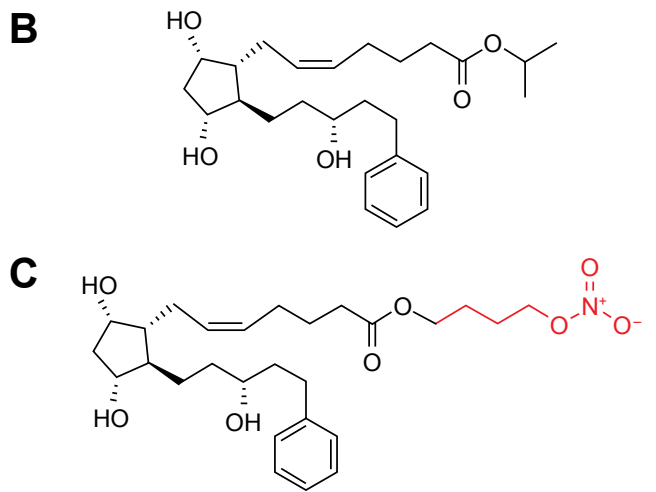

Figure I Molecular structures of (A) PGF $_{2 \alpha},(\mathbf{B})$ latanoprost, and (C) LBN. Notes: Both latanoprost and LBN contain a latanoprost acid backbone. In contradistinction to latanoprost, however, LBN integrates an NO-donating moiety (red) in lieu of an isopropyl ester.

Abbreviations: $\mathrm{PGF}_{2 \alpha}$, prostglandin $\mathrm{F}_{2 \alpha}$; $\mathrm{LBN}$, latanoprostene bunod; $\mathrm{NO}$, nitric oxide.

(FP receptor) agonist. FP receptors have been identified in the ciliary muscle, ciliary epithelium, and sclera, and an in vitro analysis has revealed significant PGA agonist activity at cloned human ciliary body FP receptors. ${ }^{11,12}$ Latanoprost acid increases aqueous humor drainage primarily by reducing outflow resistance through the uveoscleral pathway. This is thought to occur by an increased expression of matrix metalloproteinases (MMPs) relative to their inhibitors (tissue inhibitors of metalloproteinases). Most notably, enhanced expression $^{13}$ of MMP-1, -3, and -9 promotes degradation of collagen types I, III, and IV in the longitudinal bundles of the ciliary muscle ${ }^{14-16}$ and surrounding sclera. ${ }^{17-19}$ The resulting extracellular matrix remodeling yields increased permeability and reduced outflow resistance. Latanoprost-enhanced ciliary muscle permeability may be further augmented by morphologic changes in ciliary muscle cells caused by actin and vinculin reorganization. ${ }^{20}$

In humans, latanoprost acid has also been demonstrated to increase conventional outflow through the TM and $\mathrm{SC}$, although the impact is minor compared to the enhancement of uveoscleral outflow. ${ }^{21-22}$ The mechanism of this effect has not been fully elucidated, but is likely similar to latanoprost's action on the ciliary muscle and sclera, involving MMPmediated reorganization of the TM extracellular matrix milieu. ${ }^{19}$ This is supported by the presence of FP receptors on human TM cells, at which PGAs exert agonistic activity. ${ }^{12,21}$ Furthermore, latanoprost has also been demonstrated to 


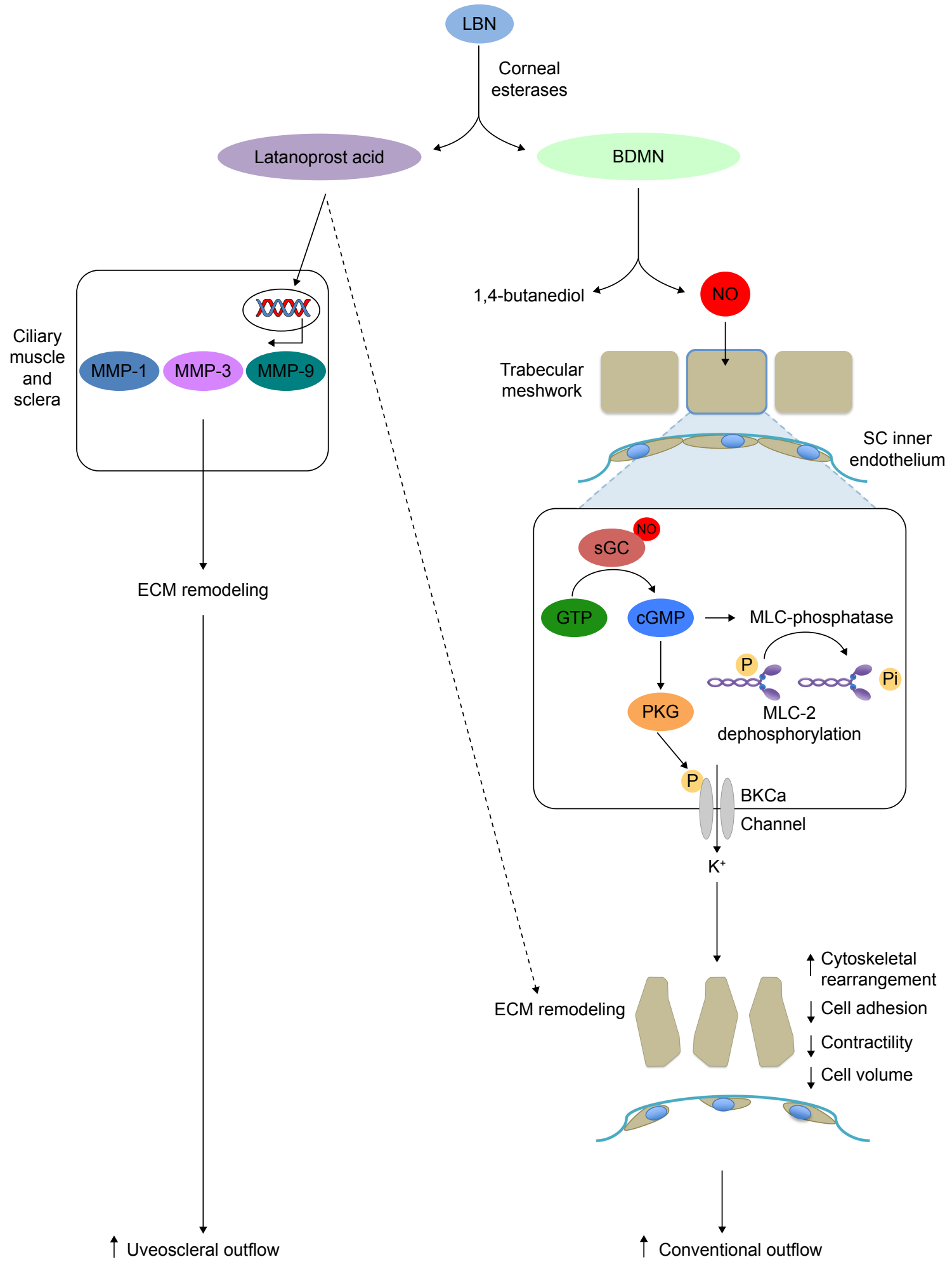

Figure 2 Putative mechanism of action of LBN.

Notes: Upon topical administration at the ocular surface, LBN is hydrolyzed by corneal esterases into latanoprost acid and BDMN. Latanoprost acid (left), the active component of latanoprost ophthalmic solution (Xalatan), increases expression of matrix metalloproteinases (MMP-I, -3 , and -9 ) in the ciliary muscle, which promote remodeling of the ciliary muscle ECM and subsequent increased aqueous humor outflow through the uveoscleral route. MMPs additionally may augment conventional outflow through SC via TM remodeling (minor pathway, dashed arrow). NO released from BDMN (right) enters cells of the TM and inner wall of SC, leading to dephosphorylation of MLC-2 and efflux of potassium ions through BKCa channels. These changes promote decreases in cell contractility and volume, as well as rearrangement of the actin cytoskeleton. The altered biomechanical properties of TM and SC cells allow for enhanced conventional outflow.

Abbreviations: GTP, guanosine triphosphate; sGC, soluble guanylate cyclase; cGMP, cyclic guanosine monophosphate; PKG, protein kinase G; P, phosphate; Pi, inorganic phosphate; LBN, latanoprostene bunod; BDMN, butanediol mononitrate; ECM, extracellular matrix; MMPs, matrix metalloproteinases; SC, Schlemm's canal; TM, trabecular meshwork; NO, nitric oxide; MLC-2, myosin light chain-2; BKCa, large-conductance calcium-activated potassium channel. 
induce cyclooxygenase-2-dependent expression of MMP-1 by nonpigmented ciliary epithelium cells. ${ }^{23}$ Subsequent diffusion of MMP-1 to the ciliary muscle and TM may augment outflow through both pathways.

The PGA metabolite of the LBN prodrug recapitulates the effects of latanoprost on both the uveoscleral and conventional outflow pathways. The unique NO component, however, exerts additional pharmacologic action on the conventional outflow pathway that is not characteristic of latanoprost and other PGAs.

Although NO-donating compounds have been used in medicine for over a century, LBN is among the first to be evaluated for topical ophthalmic use. The ocular hypotensive effects of NO-releasing molecules have been well characterized in animal and in vitro studies. NO-donating compounds have been demonstrated to lower IOP in animal models of glaucoma and OHTN, ${ }^{24-28}$ as well as in humans with OAG and angle-closure glaucoma upon oral administration. ${ }^{29}$

NO is a gas and can freely diffuse across plasma membranes. The relaxing effect of NO and its second messenger, cyclic guanosine monophosphate (cGMP), on vascular smooth muscle cells has been well described; ${ }^{30}$ in fact, these discoveries by Louis Ignarro, Robert Furchgott, and Ferid Murad earned them the Nobel Prize in Physiology and Medicine in 1998. TM cells, like vascular smooth muscle cells, are highly contractile and may therefore respond to NO in a similar fashion. In cultured human TM cells, NO donors induce a reduction in cell volume and contractility. ${ }^{31}$ These effects are dependent upon soluble guanylate cyclase (sGC), protein kinase $\mathrm{G}$ (PKG), and large-conductance calcium-activated potassium (BKCa) channels and are mimicked by radiolabeled cGMP. ${ }^{31,32}$ Dismuke et al ${ }^{31}$ therefore proposed that NO induces these TM cell morphologic and biomechanical changes by activation of the sGC/cGMP/ PKG pathway, leading to phosphorylation of BKCa channels and subsequent efflux of potassium ions. These changes also correspond to a decrease in myosin light chain (MLC) phosphorylation $^{33}$ - which may further promote TM cell relaxation ${ }^{34}$ - and are associated with increased outflow facility in perfused porcine anterior segments. ${ }^{31} \mathrm{NO}$-mediated increase in conventional outflow, with corresponding cGMP increase, has also been demonstrated in anterior segments of human donor eyes. ${ }^{24}$

NO may also induce relaxation of the inner wall of $\mathrm{SC}^{35}$ and reduction in $\mathrm{SC}$ endothelial cell volume via the sGC/cGMP/PKG cascade ${ }^{36}$ and subsequent disruption of intercellular adherens junctions. ${ }^{37}$ These biomechanical changes likely further enhance the egress of aqueous via the conventional outflow tract. NO might also act downstream of SC by promoting relaxation of smooth muscle cells surrounding collector channels to decrease distal outflow resistance. ${ }^{38}$ In addition, although NO may modulate episcleral venous pressure (EVP), this process has not been fully elucidated. Investigations of the effects of topical NO donors on EVP have yielded discrepant results, with some authors reporting a decrease in $\mathrm{EVP}^{39}$ and others describing an increase. ${ }^{40,41}$ In the episcleral circulation, NO likely primarily causes vasodilation of arterioles and arteriovenous anastomoses rather than acting upon veins, thereby increasing blood flow to veins and subsequently elevating the EVP. ${ }^{39}$ In contrast, the effect of latanoprost acid on EVP is likely minimal. ${ }^{21}$

Animal model and in vitro studies of LBN, in particular, lend credence to the putative effects of NO donors on TM and also provide further mechanistic insights (Table 1). Data from Saeki et $\mathrm{al}^{42}$ suggest that the NO-associated effects

Table I Preclinical studies of latanoprostene bunod ${ }^{\mathrm{a}}$

\begin{tabular}{|c|c|c|c|}
\hline Authors (Year) & Model (Pathology) & Findings & Conclusions \\
\hline Saeki et al ${ }^{42}(2009)$ & Mouse & $\begin{array}{l}\text { LBN and LAT yield similar IOP reduction in } \\
\text { wild-type mice } \\
\text { LBN reduces IOP in FP receptor knockout mice; } \\
\text { LAT does not }\end{array}$ & $\begin{array}{l}\text { NO donation by LBN involved in IOP } \\
\text { reduction }\end{array}$ \\
\hline $\begin{array}{l}\text { Krauss et al }{ }^{43}(2009) \\
\text { Krauss et al }(201 \mathrm{I})\end{array}$ & $\begin{array}{l}\text { Monkey }(\mathrm{OHT}) \\
\text { Dog (glaucoma) } \\
\text { Rabbit }(\mathrm{OHT})\end{array}$ & $\begin{array}{l}\text { LBN lowered IOP to a greater degree than LAT } \\
\text { LBN, but not LAT, increases anterior segment } \\
\text { cGMPb }^{\text {b }}\end{array}$ & $\begin{array}{l}\text { Greater effect of LBN likely result of NO } \\
\text { donation }\end{array}$ \\
\hline $\begin{array}{l}\text { Cavet et } \mathrm{al}^{44}(2014) \\
\text { Cavet et } \mathrm{al}^{45}(2015)\end{array}$ & Human TM cell & $\begin{array}{l}\text { LBN, in contrast to LAT, greatly increases cGMP } \\
\text { and reduces MLC- } 2 \text { phosphorylation } \\
\text { LBN produces more cell relaxation and less cell } \\
\text { adhesion compared to LAT }\end{array}$ & $\begin{array}{l}\text { NO donation by LBN achieves relaxation } \\
\text { via increased cGMP signaling } \\
\text { LBN likely enhances conventional } \\
\text { outflow }\end{array}$ \\
\hline
\end{tabular}

Notes: ${ }^{a}$ Studied as PF-03I87207 (Sakei et al, ${ }^{42}$ Krauss et al ${ }^{43}$ 2009) and BOL-303259-X (Krauss et al9 201 I). bMeasured in rabbits only.

Abbreviations: LBN, latanoprostene bunod; LAT, latanoprost; FP, prostaglandin $\mathrm{F}_{2 \alpha}$; NO, nitric oxide; IOP, intraocular pressure; OHT, ocular hypertension; cGMP, cyclic guanosine monophosphate; TM, trabecular meshwork; MLC-2, myosin light chain-2. 
of LBN are independent from the PGA-mediated effects. In $\mathrm{PGF}_{2 \alpha}$ receptor (FP receptor) knockout mice, $\mathrm{LBN}$ yielded significant IOP reduction, whereas latanoprost did not. The IOP-lowering effects of LBN persist even when FP signaling is abolished indicate that the effects of NO donation alone may be sufficient to reduce IOP. Krauss et $\mathrm{al}^{9,43}$ report that topical administration of $\mathrm{LBN}$ resulted in significant IOP reduction in three animal models of elevated IOP. These IOP-lowering effects are associated with increases in anterior segment cGMP and latanoprost acid concentrations.

Studying endothelin-1-contracted human TM cells, Cavet et $\mathrm{al}^{44,45}$ similarly found increases in sGC-dependent cGMP concentrations after treatment with LBN. This was associated with diminutions in MLC-2 phosphorylation, F-actin-mediated contractility, and vinculin-associated adhesion of TM cells to underlying substrate. These biochemical and structural changes were significantly greater with LBN compared to latanoprost. These data suggest that the NO/ cGMP signaling cascade triggered by other NO-releasing compounds in TM cells is also likely induced by LBN, promoting rearrangement of cytoskeletal architecture, increased cell relaxation, and reduced cell adhesion.

The potent actions of LBN on both the uveoscleral and conventional outflow pathways have been hypothesized to enhance its ocular hypotensive effects in comparison to other PGAs.

\section{Pharmacokinetics}

The ocular and systemic pharmacokinetics of LBN in humans has not been well described. However, ocular pharmacokinetic parameters have been characterized in mammalian model studies. Krauss et $\mathrm{al}^{9,43}$ measured concentrations of latanoprost acid in anterior segment structures of rabbits and monkeys after administration of topical LBN $0.01 \%$ versus latanoprost $0.012 \%$. Peak concentration of latanoprost acid in these anterior segment structures was similar between the two compounds, suggesting comparable penetration rates. Following instillation of $\mathrm{LBN}$ versus latanoprost in rabbits, time to maximum concentration $\left(T_{\max }\right)$ of latanoprost acid was identical for the two drugs as measured in cornea ( 0.5 hours), aqueous ( 1 hour), and iris/ciliary body ( 1 hour). In monkeys, $T_{\max }$ of latanoprost acid was similar for the two drugs as measured in cornea ( 0.5 hours) and aqueous ( 0.5 hours), but longer for LBN ( 1 hour) compared to latanoprost ( 0.5 hours) as measured in iris/ciliary body.

Half-life $\left(T_{1 / 2}\right)$ of latanoprost acid in anterior segment compartments was also similar after administration of the two drugs. In rabbits, $T_{1 / 2}$ after application of LBN was 1.8 hours in cornea, 2.1 hours in aqueous, and 4.6 hours in iris/ciliary body. These were not statistically significantly different from $T_{1 / 2}$ after instillation of latanoprost (1.7 hours in cornea, 3.0 hours in aqueous, and 2.6 hours in iris/ ciliary body).

Importantly, however, these pharmacokinetic data for the monkey model were obtained from a limited sample size $(\mathrm{N}=2)$ that precluded statistical comparison of these parameters between the two compounds.

The metabolism of the latanoprost acid component of LBN may be similar to that of latanoprost acid derived from latanoprost, although this has not been demonstrably verified. In adult humans, latanoprost acid derived from latanoprost reaches a maximum concentration of $53 \mathrm{pg} / \mathrm{mL}$ in the systemic circulation 5 minutes after administration. It is metabolized by the liver and excreted primarily in the urine. ${ }^{46}$

\section{Efficacy and comparative studies Preclinical studies}

All preclinical basic science studies of LBN were sponsored by or performed in collaboration with Pfizer, Inc. or Bausch + Lomb. These studies have highlighted the superior ocular hypotensive effects of topical LBN compared to latanoprost in animal and in vitro models (Table 1). In beagles with glaucoma, LBN produced a 34\% maximal decrease in IOP (approximately $9.2 \mathrm{mmHg}$, adjusting for decrease associated with LBN vehicle) at 2 hours after dosing. ${ }^{9}$ Equimolar latanoprost $(0.030 \%)$, in contrast, was associated with an 18\% maximal IOP reduction (approximately $4.5 \mathrm{mmHg}$, adjusting for decrease associated with latanoprost vehicle) at 6 hours postadministration.

The comparatively greater efficacy of LBN to latanoprost has also been demonstrated in cynomolgus monkeys with OHTN secondary to laser-induced trabecular photocoagulation, ${ }^{9}$ a model that is sensitive to the pharmacologic effects of high-dose latanoprost. ${ }^{47,48}$ Interestingly, IOP reduction in this model after instillation of LBN $0.030 \%$ was more profound than that of both equimolar and highdose $(0.10 \%)$ latanoprost, suggesting that the NO-mediated activity of $\mathrm{LBN}$ is robust in the context of a significantly restricted conventional outflow. $\mathrm{LBN}$ was associated with a $28 \%$ maximal reduction of IOP (approximately $13.6 \mathrm{mmHg}$ ) within 6 hours of instillation, whereas equimolar latanoprost did not produce a statistically significant reduction in IOP. High-dose latanoprost yielded a maximal 14.3\% diminution in IOP (approximately $6.1 \mathrm{mmHg}$ ), which was still inferior to the ocular hypotensive effect of LBN. 
As both LBN and latanoprost were associated with similar ocular penetration rates in animal models (see "Pharmacokinetics" section), the greater IOP-lowering effects observed with LBN were likely a consequence of the NO moiety. ${ }^{9}$ This is corroborated by the observation that LBN produced significant reduction in IOP in pigmented rabbits, which are not sensitive to PGF2 $\alpha$ agonists. ${ }^{49,50}$ In this rabbit model with transient saline-induced OHTN, LBN $0.036 \%$ was associated with a $30 \%$ mean decrease in IOP $(-13.5 \pm 2.0 \mathrm{mmHg})$, with maximal effect at $0.5-1.5$ hours after instillation. ${ }^{9}$ Conversely, equimolar latanoprost did not produce a statistically significant diminution in IOP in this model.

Cavet et $\mathrm{al}^{44,45}$ demonstrated greater reductions in in vitro human TM cell contractility and adhesion with LBN compared to latanoprost, lending insight into the mechanistic basis underlying the greater ocular hypotensive activity of LBN. Only one preclinical study found no significant difference in the efficacy of the two drugs, with LBN $0.006 \%$ and latanoprost $0.005 \%$ producing similar IOP-lowering effects in a wild-type mouse model for up to 6 hours after administration. ${ }^{42}$ Superiority of LBN to latanoprost was observed, however, in FP-receptor knockout mice, highlighting the role of NO in lowering IOP.

\section{Clinical experiments}

To date, eight US Food and Drug Administration clinical trials of LBN involving human subjects have been performed since 2007 (Table 2). All trials were sponsored by Pfizer, Inc. or Bausch + Lomb. Complete methodology and results have been published under peer review for four of these trials. In all efficacy and comparative studies described herein, one drop of LBN or a comparative agent was administered topically to subjects in the dosing regimen specified. Efficacy outcomes of six major trials are summarized in Figure 3, depicting the IOP-lowering effects of LBN compared to those of latanoprost and timolol.

\section{Phase I trials}

KRONUS: proof of principle (ClinicalTrials.gov Study ID: NCTO 1895985)

KRONUS $^{51-53}$ is the only Phase I trial of LBN performed to date. This trial was performed after dose-finding studies (see "Phase II Trials"; "VOYAGER" sections), ${ }^{54-57}$ and as such evaluated LBN $0.024 \%$, which previously demonstrated optimal efficacy and safety profile.

This single-arm, controlled, open-label study performed at a single center in Japan assessed the effects on IOP of topical LBN $0.024 \%$ dosed once daily at 8 PM for 14 days in healthy adult Japanese males with no ocular pathology (mean age $=26.8 \pm 6.3$ years; mean baseline IOP $=13.6 \pm 1.3 \mathrm{mmHg}$ ). IOP measurements were recorded at nine time points over a 24-hour monitoring period on day 14; the primary efficacy end point was change in IOP from baseline at all of these time points. A reduction in IOP was observed at all time points $(P<0.001)$, with a $27 \%$ mean reduction $(3.6 \pm 0.8 \mathrm{mmHg})$ across 24 hours. Maximal IOP-lowering $(30 \%, 4.2 \pm 1.8 \mathrm{mmHg})$ occurred 12 hours after dosing, while trough IOP decrease $(20 \%, 2.8 \pm 2.2 \mathrm{mmHg})$ occurred 24 hours postadministration (at $8 \mathrm{AM}$ and $8 \mathrm{PM}$, respectively).

The results of this pivotal trial serve as proof of principle of the profound IOP reduction associated with LBN $0.024 \%$ monotherapy. The demonstration of potent IOP lowering over 24 hours in Japanese subjects with normal IOP may also justify the clinical evaluation of LBN in normal tension glaucoma, which is common in Japanese populations ${ }^{58}$ and may be associated with diurnal fluctuations in IOP. ${ }^{59,60}$

\section{Phase II trials}

\section{ClinicalTrials.gov Study ID: NCT0044I883}

NCT00441883 was the first trial of LBN in human subjects. This was a controlled, randomized, parallel-group, doublemasked, dose-finding study comparing the safety and efficacy of LBN (PF-03187207) to latanoprost at multiple centers in the USA. Adult subjects with POAG, OHTN, pigmentary glaucoma, and pseudoexfoliative glaucoma were recruited, resulting in a total of 242 enrolled. Subjects were randomized to receive either one of five doses of LBN ranging from $0.003 \%$ to $0.040 \%$, or latanoprost $0.005 \%$, dosed once daily in the study eye. Outcomes included change in IOP from baseline at 7, 14, 21, and 28 days after study commencement and proportion of individuals reaching target IOPs. Complete methodology - including exact timing and frequency of dosing, timing of IOP measurement, as well as target IOPs and results remain unpublished to date. Partial dose-finding results, however, were presented in the form of a metaanalysis estimating a median effective dose of $0.0054 \% / \mathrm{d}$ and maximal IOP lowering of $6.90 \mathrm{mmHg} .{ }^{61}$

\section{ClinicalTrials.gov Study ID: NCT00595 I0I}

Similar to NCT00441883 in the USA, this controlled, randomized, double-masked, dose-finding study at multiple sites in Japan assessed the safety and efficacy of LBN (PF-03187207) compared to latanoprost in adult patients with POAG or OHTN. Subjects were randomized to receive one of five concentrations of $\mathrm{LBN}$ ranging from $0.003 \%$ to $0.040 \%$, or latanoprost $0.005 \%$ dosed once daily either in the morning (qAM) or evening (qPM). IOP was measured at baseline and 
Table 2 Latanoprostene bunod ${ }^{\text {a }}$ clinical developmental programs as of June 2016

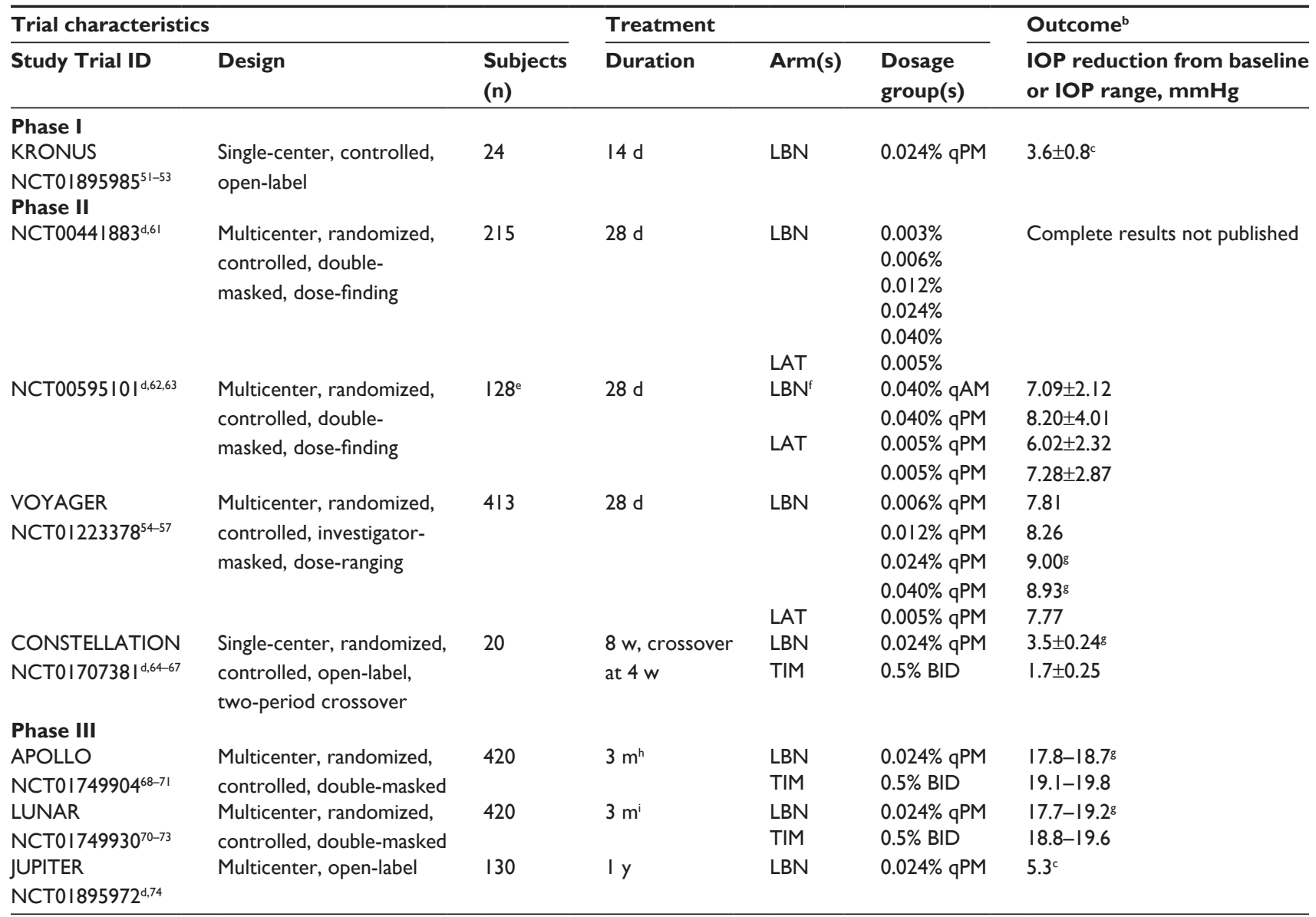

Notes: aStudied as PF-03 87207 (NCT0044I883, NCT00595I0I), BOL-303259-X (VOYAGER, CONSTELLATION, APOLLO, LUNAR), and Vesneo TM (CONSTELLATION) 'Primary efficacy outcome at the study's primary endpoint; for trials with multiple primary endpoints, data from either, I) the longest interval after treatment initiation or, 2 ) the largest reduction in IOP, are presented. Numerical values are presented as mean \pm standard deviation, if known. 'Statistically significantly different from baseline. ${ }^{\mathrm{d}}$ Complete methodology and results of trial not published to date. ${ }^{\mathrm{e}}$ Discrepant numbers of enrolled patients in this trial have been reported. ${ }^{\mathrm{f}} \mathrm{Comparisons}$ of $0.003 \%$, $0.006 \%$,

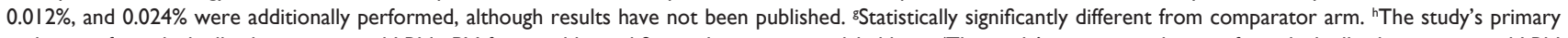
endpoint, after which all subjects received LBN qPM for an additional 9 months on an open-label basis. 'The study's primary endpoint, after which all subjects received LBN qPM for an additional 3 months on an open-label basis. Adapted by permission from BMJ Publishing Group Limited. A randomised, controlled comparison of latanoprostene bunod and latanoprost $\mathbf{0 . 0 0 5 \%}$ in the treatment of ocular hypertension and open angle glaucoma: the VOYAGER study. Weinreb RN, Ong T, Scassellati Sforzolini B, et al. Br J Ophthalmol. (C) 2015;99(6):738-745..$^{54}$ Data from Weinreb RN, Scassellati Sforzolini B, Vittitow J, Liebmann J. Latanoprostene bunod 0.024\% versus timolol maleate $0.5 \%$ in subjects with open-angle glaucoma or ocular hypertension: the APOLLO Study. Ophthalmology. 20I6; I23(5):965-973.68 Data from Medeiros FA, Martin KR, Peace J, Scassellati Sforzolini B, Vittitow JL, Weinreb RN. Comparison of Latanoprostene Bunod $0.024 \%$ and Timolol Maleate 0.5\% in Open-Angle Glaucoma or Ocular Hypertension: the LUNAR Study. Am J Ophthalmol. Epub 2016 May $19 .{ }^{72}$

Abbreviations: IOP, intraocular pressure; LBN, latanoprostene bunod; LAT, latanoprost; TIM, timolol maleate; qAM, every morning; qPM, every evening; BID, twice daily; $\mathrm{d}$, days; w, weeks; m, months; $y$, year.

at four time points after dosing (days 7, 14, 21, and 28), at 8 AM, 10 AM, 1 PM and 4 PM on each of these days. The primary efficacy end point was change in mean diurnal IOP in the study eye on day 28 , and secondary efficacy measures included IOP at day 7, 14, and 21 as well as a proportion of subjects reaching target IOPs on these days.

Only partial methodology and results of this trial have been published. ${ }^{62,63}$ Reduction in IOP with LBN $0.040 \%$ qPM was numerically greatest compared to IOP lowering with other LBN formulations as well as latanoprost qAM and qPM, although these differences were not statistically significant at the primary end point. Mean difference between LBN $0.040 \%$ qPM and latanoprost qPM, however, was statistically significant on day $21(1.86 \mathrm{mmHg} ; P=0.017)$. (The reporting of these results involves discrepancies in the number of enrolled patients, with 128 documented by ClinicalTrials.gov, 176 reported by Bosworth et al, ${ }^{62}$ and 133 noted by Raber et $\mathrm{al}^{63}$ ).

\section{VOYAGER: pivotal comparison to latanoprost (ClinicalTrials.gov Study ID: NCTO I223378)}

As a controlled, randomized, investigator-masked, dosefinding study at multiple centers in the USA and EU, this pivotal study compared the safety and efficacy of LBN (BOL-303259-X) and latanoprost in adult subjects with OHTN or OAG, including pseudoexfoliative and pigmentary 


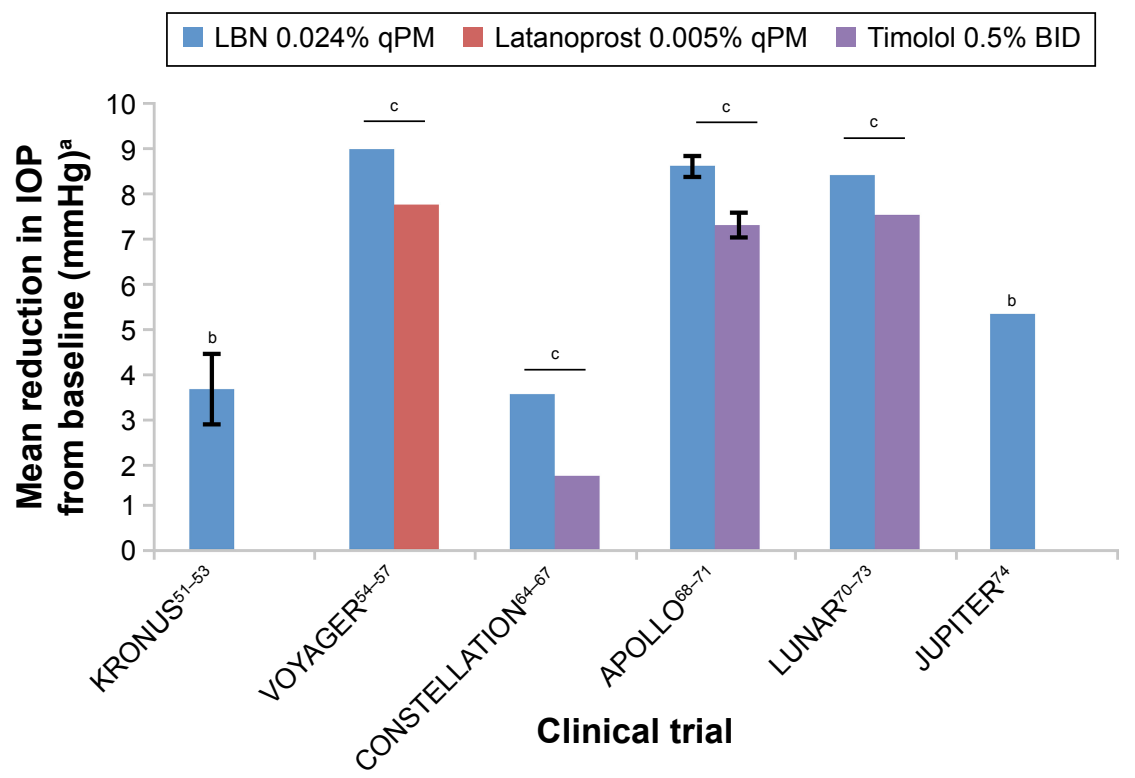

Figure 3 Mean reduction in IOP from baseline associated with LBN $0.024 \%$ qPM, latanoprost $0.005 \%$ qPM, and timolol $0.5 \%$ BID from six major clinical trials. Notes: Error bars represent standard deviation (if reported). ${ }^{a}$ Reduction in mean diurnal IOP at the study's primary endpoint, with the exception of data from JUPITER, in which IOP was measured only once on study visit days. For trials with multiple primary endpoints (APOLLO and LUNAR), the maximal mean reduction from baseline in diurnal IOP is presented. bStatistically significantly different from baseline IOP. 'Significantly different from comparator arm. Adapted by permission from BMJ Publishing Group Limited. A randomised, controlled comparison of latanoprostene bunod and latanoprost $0.005 \%$ in the treatment of ocular hypertension and open angle glaucoma: the VOYAGER study. Weinreb RN, Ong T, Scassellati Sforzolini B, et al. Br J Ophthalmol. @ 2015;99(6):738-745. ${ }^{54}$

Abbreviations: IOP, intraocular pressure; LBN, latanoprostene bunod; qPM, every evening; BID, twice daily.

glaucoma. ${ }^{54-57}$ VOYAGER also sought to determine the optimal dose of LBN in lowering IOP. This was the first comparative study with latanoprost detailing all clinical methodology and results, including all adverse events. Subjects (mean age $=61.0 \pm 11.44$ years; range of mean baseline IOPs in treatment groups $=26.01 \pm 1.67-26.25 \pm 1.79 \mathrm{mmHg}$ ) were randomized to receive one of four LBN concentrations or latanoprost $0.005 \%$ in the study eye once daily at $8 \mathrm{PM}$ for 28 days.

Mean diurnal IOP (average of readings at $8 \mathrm{AM}, 12 \mathrm{PM}$, and 4 PM) was assessed at baseline and on days 7, 14, 28, and 29 . The primary efficacy measure was change in mean diurnal IOP from baseline at day 28 . Secondary efficacy outcomes were as follows: 1) change in mean diurnal IOP from baseline on days 7,14 , and 29;2) change from baseline IOP at each of the three measurement time points on measurement days; 3) percentage of individuals with IOP of $18 \mathrm{mmHg}$ or less at measurement time points.

Of 413 subjects randomized, 396 completed the study (LBN $0.006 \%, \mathrm{~N}=76$; LBN $0.012 \%, \mathrm{~N}=81$; LBN $0.024 \%$, $\mathrm{N}=80 ; \mathrm{LBN} 0.040 \%, \mathrm{~N}=80$; latanoprost, $\mathrm{N}=79$ ). Primary and secondary efficacy end points demonstrated greater IOPlowering activity of LBN $0.024 \%$ and $0.040 \%$ compared to latanoprost. The IOP-reducing effect of LBN was dosedependent, plateauing at $0.024 \%$. The greatest diurnal IOP reductions with LBN on day 28 were $9.00 \mathrm{mmHg}(0.024 \%)$ and $8.93 \mathrm{mmHg}(0.040 \%)$; standard deviations not reported. These were the only statistically significantly greater changes ( $P=0.005$ and 0.009 , respectively) compared to IOP reduction with latanoprost $(7.77 \mathrm{mmHg})$.

LBN $0.024 \%$ also showed significantly greater mean diurnal IOP reduction compared to latanoprost on day 7 $(P=0.033)$ and day $14(P=0.015)$, but not 36-44 hours after last instillation of each (day 29; $P=0.051$ ). Among these measurement points, LBN $0.040 \%$ was superior to latanoprost only on day $7(P=0.009)$. LBN $0.024 \%$ demonstrated significantly greater reduction in IOP than latanoprost at multiple specified time points, with the exception of the 8 AM measurements on day 7 and day 21 , as well as the $8 \mathrm{AM}$ and $12 \mathrm{PM}$ measurements on day $29(P>0.05$ for each). Of note, LBN $0.024 \%$ still showed a greater effect than latanoprost at $4 \mathrm{PM}$ on day 29, 36-44 hours after cessation of therapy $(P=0.045)$. LBN $0.040 \%$ similarly produced a greater IOP reduction compared to latanoprost at several specified time points, with the exception of $8 \mathrm{AM}$ on day 7 , $8 \mathrm{AM}$ and $12 \mathrm{PM}$ on day 14 , and all time points on day 29 $(P>0.05$ for each).

The LBN $0.024 \%$ group also had a significantly greater percentage of individuals with mean diurnal IOP $\leq 18$ $\mathrm{mmHg}$ compared to that in the latanoprost group on all 
measurement visits after treatment commenced (days 7, 14, 28, 29; $P \leq 0.046$ for each). The LBN $0.040 \%$ group had a greater percentage versus the latanoprost group on days 7 $(P=0.007)$ and $28(P=0.039)$.

\section{CONSTELLATION: initial comparison to timolol (ClinicalTrials.gov Study ID: NCT0I70738I)}

CONSTELLATION was the first trial to compare the efficacy and safety of LBN (BOL-303259-X) and timolol. ${ }^{64-67}$ In this controlled, open-label, two-period crossover study at a single center in the USA, 20 adult subjects with OAG or OHTN were randomized $1: 1$ and first given either LBN $0.024 \%$ daily at $8 \mathrm{PM}$ or timolol maleate $0.5 \%$ twice daily (BID; $8 \mathrm{AM}$ and $8 \mathrm{PM}$ ) in the study eye (Period 1). After 4 weeks of treatment, subjects were crossed over to the comparator arm for four additional weeks (Period 2). To date, this has been the only study of LBN with crossover data as the primary efficacy end point. Mean diurnal IOP was measured every 2 hours during a 24-hour period at baseline, 4 weeks (end of Period 1), and 8 weeks (end of Period 2). Primary efficacy end point was change in mean 24-hour IOP from baseline from both periods.

Mean change in 24-hour IOP after treatment was significantly greater for LBN $(3.5 \pm 0.24 \mathrm{mmHg})$ than for timolol $(1.7 \pm 0.25 \mathrm{mmHg} ; P<0.05)$. This change was also numerically greater for LBN during the diurnal period $(3.9 \pm 0.28$ versus $2.4 \pm 0.29 \mathrm{mmHg})$ and nocturnal period $(2.75 \pm 0.45$ versus $0.2 \pm 0.46 \mathrm{mmHg}$ ); the statistical significance of these differences, however, was not specified.

\section{Phase III trials \\ APOLLO: pivotal, large-scale comparison to timolol (ClinicalTrials.gov Study ID: NCTOI 749904)}

This pivotal randomized, controlled, double-masked trial, evaluated the efficacy and safety of LBN (BOL-303259-X) compared to timolol on a large scale and with a noncrossover design for primary end points. ${ }^{68-71}$ Four hundred and twenty adult subjects with OHTN or OAG, including pseudoexfoliative and pigmentary glaucoma, at multiple centers throughout the USA and EU were randomized 2:1 to receive either LBN $0.024 \%$ once daily at $8 \mathrm{PM}$ or timolol maleate $0.5 \% \mathrm{BID}$ (8 AM and $8 \mathrm{PM}$ ) in the study eye for 3 months.

The primary efficacy outcome was IOP recorded at three time points - 8 AM, $12 \mathrm{PM}$, and $4 \mathrm{PM}$ - at postbaseline visits 2 weeks, 6 weeks, and 3 months after treatment commenced. Secondary end points included the following: 1) percentage of subjects with IOP $\leq 18 \mathrm{mmHg}$ at all nine measurement time points; 2) percentage of subjects with $25 \%$ or greater decrease in IOP from baseline at all nine measurement time points; 3) change in IOP from baseline at each time point; 4) change in diurnal IOP (average of 8 AM, 12 PM, and 4 PM readings) from baseline at each postbaseline visit.

Three hundred and eighty seven patients completed the study ( $\mathrm{LBN}, \mathrm{N}=263$; timolol, $\mathrm{N}=124$ ). The results demonstrated that IOP was significantly lower in the LBN group (range $=17.8-18.7 \mathrm{mmHg}$ ) than in the timolol group (range $=19.1-19.8)$ at all nine time points $(P \leq 0.002$ for each). Of note, the greater efficacy of LBN at these time points did not differ based on subject age ( $<65$ versus 65 years or older) or prior treatment status.

In the LBN group, a significantly higher proportion of subjects $(22.9 \%)$ had IOP measurements $\leq 18 \mathrm{mmHg}$ at all nine time points than in the timolol group $(11.3 \% ; P=0.005)$. Similarly, the LBN group had a greater percentage $(34.9 \%)$ with an IOP decrease of $\geq 25 \%$ from baseline at all nine time points than in the timolol group (19.5\%; $P=0.001)$. In addition, IOP decrease from baseline was superior at all nine time points in the LBN group (range $=7.7-9.1 \mathrm{mmHg}$ ) versus in the timolol group (range $=6.6-8.0 \mathrm{mmHg}$; standard deviations not reported), with $P \leq 0.002$ for each time point. Decrease in diurnal IOP was significantly greater at all three postbaseline visits for $\mathrm{LBN}$ (range $=8.4-8.6 \mathrm{mmHg}$ ) compared to timolol (range $=7.1-7.3 \mathrm{mmHg}$ ), with $P<0.001$ for each visit (standard deviations not reported).

After completion of the 3-month treatment phase, all subjects were administered LBN $0.024 \%$ qPM for an additional 9 months as part of an open-label safety extension phase; IOP measurements were recorded during this time period at 6,9 , and 12 months postrandomization. These results were pooled with data from the LUNAR study (see "LUNAR" section), with a total of 737 subjects completing these extension phases. ${ }^{70} \mathrm{LBN}$ demonstrated sustained IOP lowering compared to baseline over 12 months, with a reduction from baseline in mean diurnal IOP among all subjects ranging from $32 \%$ to $34 \%(P<0.001$ at each time point). Importantly, subjects crossed over to LBN from timolol during this phase experienced an additional $6.3 \%-8.3 \%$ diminution in mean diurnal IOP.

\section{LUNAR (ClinicalTrials.gov Study ID: NCT0I749930)}

LUNAR was a randomized, double-masked study comparing the efficacy and safety of LBN (BOL-303259-X) to timolol at multiple sites in the USA and EU. ${ }^{70-73}$ The design and efficacy end points of this study were comparable to those of APOLLO; however, the open-label safety extension phase lasted 3 months after treatment, as opposed to 9 months as 
in APOLLO. Four hundred and twenty adults with OAG or OHTN were randomized 2:1 to receive a 3-month regimen of either LBN $0.024 \%$ qPM or timolol $0.05 \%$ BID in the study eye. Three hundred and eighty seven subjects completed the trial (LBN, $\mathrm{N}=259$; timolol, $\mathrm{N}=128$ ).

At almost all nine time points measured over 3 months (with the exception of the week 2 measurement at 8 AM), mean IOP was significantly lower with LBN than with timolol $(P \leq 0.025)$. IOP at these time points ranged from 17.7 to 19.2 $\mathrm{mmHg}$ with LBN and 18.8 to $19.6 \mathrm{mmHg}$ with timolol. Reduction in mean diurnal IOP was also significantly greater at all visits $(P \leq 0.034)$ with LBN compared to timolol ( 8.0 versus $7.3,8.4$ versus 7.5 , and 8.4 versus $7.3 \mathrm{mmHg}$ at weeks 2,6 , and 12 , respectively; standard deviation values not specified). ${ }^{73}$ Around $17.7 \%$ of subjects demonstrated IOP lowering to a target of $\leq 18 \mathrm{mmHg}$ at all nine time points, compared to $11.1 \%$ with timolol, although unlike in APOLLO this was not statistically significant $(P=0.084)$. Conversely, $31.0 \%$ of subjects in the LBN group had a reduction from baseline in IOP of $\geq 25 \%$, versus only $18.5 \%$ in the timolol group; this difference was statistically significant $(P=0.007)$.

After completion of the 3-month treatment phase, all subjects were administered LBN $0.024 \%$ qPM for an additional 3 months as part of an open-label safety extension phase; IOP measurements were recorded during this time period at 6 months postrandomization. These results were pooled with data from the APOLLO study; all subjects demonstrated IOP lowering from baseline over this period (see “APOLLO" section). ${ }^{68-71}$

\section{JUPITER (ClinicalTrials.gov Study ID: NCT0 I895972)}

JUPITER was a single-arm, open-label trial of LBN at multiple centers in Japan. Partial methodology and results of this trial have been published. ${ }^{74}$ Individuals $\geq 20$ years old with either OAG or OHTN (mean baseline IOP $=19.6 \pm 2.9 \mathrm{mmHg}$ ) were administered LBN $0.024 \%$ qPM in the study eye for a duration of 1 year. IOP was measured every 4 weeks at 10 AM, for a total of 13 time points over the treatment period. Efficacy outcomes included IOP value and change from baseline IOP at each time point. Hundred and thirty subjects were randomized, with 121 completing the study. The results demonstrated sustained IOP lowering throughout the year-long treatment period. Mean IOP was significantly decreased from baseline at all 13 points $(P<0.001$ for each), with reductions ranging from 4.3 to $5.3 \mathrm{mmHg}$ (standard deviations not reported). IOP at week 4 had decreased $22.0 \%$ from baseline to $15.3 \pm 3.0 \mathrm{mmHg}$ and was even lower at week 52 (26.3\% reduction from baseline to 14.4 $\pm 2.7 \mathrm{mmHg}$.)

\section{Safety and tolerability}

The chronic, long-term use of topical medications for management of glaucoma necessitates the development of eye drops with favorable safety and tolerability profiles. Ocular irritation and hyperemia secondary to preservatives such as benzalkonium chloride in antiglaucomatous eye drops have been well demonstrated. ${ }^{75,76}$ Various treatment-emergent adverse events (TEAEs) associated with LBN have been reported in clinical trials (Table 3 ).

Pooled data from three pivotal trials demonstrate that $22.0 \%$ of subjects experienced at least one ocular TEAE during treatment with LBN. Most ocular adverse events noted with LBN were mild and transient. The risk of serious adverse events is exceedingly low, with none documented in any study to date. The incidence of adverse events was comparable between different concentrations of LBN. ${ }^{54-57}$ The proportion of subjects experiencing ocular adverse events experienced with LBN was numerically higher compared to latanoprost (19.7\% versus $12.2 \%$ ), similar in comparison to timolol (13.4\% versus $11.9 \%$ ) in the APOLLO study, and higher compared to timolol (23.8\% versus $13.3 \%)$ in the LUNAR study.

LBN likely has no appreciable effect on visual acuity, with only $1 / 637$ pooled subjects $(0.2 \%)$ experiencing decreased visual acuity associated with treatment. Overall, LBN was associated with high tolerability and compliance, with only $1.4 \%$ of patients discontinuing therapy secondary to adverse events. However, the majority of adverse event data for LBN is derived from trials lasting 3 months or shorter. The incidence of ocular adverse events was markedly higher in the year-long JUPITER trial. ${ }^{74}$ This may indicate that the risk of developing ocular side effects increases with prolonged use.

\section{Hyperemia}

Hyperemia is among the most common side effects of glaucoma medications and similarly was among the most frequently observed adverse events of LBN in clinical trials. Across three pivotal studies, $4.9 \%$ of individuals experienced conjunctival hyperemia and $1.9 \%$ of subjects developed ocular hyperemia (as the VOYAGER study distinguished between "conjunctival hyperemia" and "ocular hyperemia", these were maintained as independent categories in the present review for statistical analysis). The incidence and severity of hyperemia did not differ among different concentrations of LBN. Compared to the incidence of hyperemia with latanoprost, the potential for an increased risk with LBN is uncertain. In head-to-head comparison with latanoprost, ocular hyperemia was more frequent with latanoprost $(8.5 \%$ 
Table 3 TEAEs ${ }^{\mathrm{a}}$ reported by three pivotal trials of LBN

\begin{tabular}{|c|c|c|c|c|}
\hline $\begin{array}{l}\text { Number subjects receiving LBN in safety } \\
\text { population }^{\text {b }}\end{array}$ & $\begin{array}{l}\text { KRONUS } \\
24\end{array}$ & $\begin{array}{l}\text { VOYAGER } \\
330-57 \\
\end{array}$ & $\begin{array}{l}\text { APOLLO }{ }^{68-71} \\
283\end{array}$ & $\begin{array}{l}\text { Pooled total } \\
637\end{array}$ \\
\hline \multicolumn{5}{|l|}{ Ocular TEAEs, $\mathbf{N}(\%)$} \\
\hline Instillation site pain & 0 & $50(15.2 \%)$ & $3(1.1 \%)$ & $53(8.3 \%)$ \\
\hline Conjunctival hyperemia & $12(50.0 \%)$ & II (3.3\%) & $8(2.8 \%)$ & $31(4.9 \%)$ \\
\hline Punctate keratitis & $13(54.2 \%)$ & $6(1.8 \%)$ & 0 & $19(3.0 \%)$ \\
\hline Ocular hyperemia & 0 & $12(3.6 \%)$ & 0 & $12(1.9 \%)$ \\
\hline Eye irritation & 0 & 0 & II (3.9\%) & II (I.7\%) \\
\hline Eye pain & I (4.2\%) & $2(0.6 \%)$ & $4(1.4 \%)$ & 7 (I.I\%) \\
\hline Dry eye & 0 & $3(0.9 \%)$ & $3(1.1 \%)$ & $6(0.9 \%)$ \\
\hline Abnormal or foreign-body sensation & 0 & $2(0.6 \%)$ & $3(1.1 \%)$ & $5(0.8 \%)$ \\
\hline Instillation site pruritus & 0 & $2(0.6 \%)$ & 0 & $2(0.3 \%)$ \\
\hline Photophobia & 0 & $2(0.6 \%)$ & 0 & $2(0.3 \%)$ \\
\hline Conjunctival disorder, unspecified & I (4.2\%) & 0 & 0 & I $(0.2 \%)$ \\
\hline Reduced visual acuity & I (4.2\%) & 0 & 0 & I $(0.2 \%)$ \\
\hline Total subjects with $\geq$ I ocular TEAE & $21(87.5 \%)$ & 81 (24.5\%) & $38(13.4 \%)$ & $140(22.0 \%)$ \\
\hline \multicolumn{5}{|l|}{ Nonocular TEAEs, $\mathbf{N}(\%)$} \\
\hline Headache & 0 & I $(0.3 \%)$ & $2(0.7 \%)$ & $3(0.5 \%)$ \\
\hline Fatigue & 0 & 0 & I (0.4\%) & I (0.2\%) \\
\hline Hair color changes & 0 & 0 & $\mathrm{I}(0.4 \%)$ & $\mathrm{I}(0.2 \%)$ \\
\hline Hair disorder, unspecified & 0 & 0 & I $(0.4 \%)$ & I $(0.2 \%)$ \\
\hline Sinus congestion & 0 & 0 & I (0.4\%) & I (0.2\%) \\
\hline Total subjects with $\geq$ I nonocular TEAE & 0 & I (0.3\%) & $5(1.8 \%)$ & $6(0.9 \%)$ \\
\hline TEAEs leading to discontinuation of therapy & 0 & $5(1.5 \%)$ & $4(1.4 \%)$ & $9(1.4 \%)$ \\
\hline
\end{tabular}

Notes: adverse events occurring on or after administration of the first treatment dose during the duration of the study. Includes all ocular TEAEs reported, irrespective of presumed etiology. Nonocular TEAEs include only those considered by the trial authors to be related to LBN treatment. Ocular TEAE data correspond to study eyes, as not all trials reported fellow treated eye TEAE data. Ocular TEAEs were reported if their incidence in the safety population eyes receiving LBN met the following criteria: $\geq 1 \%$ of treatment and fellow eyes combined (APOLLO), $\geq 2 \%$ of any LBN treatment arm (VOYAGER), or any eyes (KRONUS). ${ }^{b}$ Defined as subjects receiving at least one treatment dose. Adapted by permission from BMJ Publishing Group Limited. A randomised, controlled comparison of latanoprostene bunod and latanoprost $0.005 \%$ in the treatment of ocular hypertension and open angle glaucoma: the VOYAGER study. Weinreb RN, Ong T, Scassellati Sforzolini B, et al. Br J Ophthalmol. @ 2015;99(6):738-745. ${ }^{54}$ Adapted from Adv Ther, 32, 2015, II28-1 139, Evaluation of the effect of latanoprostene bunod ophthalmic solution, $0.024 \%$ in lowering intraocular pressure over $24 \mathrm{~h}$ in healthy Japanese subjects Araie M, Sforzolini BS, Vittitow J, Weinreb RN, copyright 2015. ${ }^{51}$ Data from Weinreb RN, Scassellati Sforzolini B, Vittitow J, Liebmann J. Latanobunod $0.024 \%$ versus timolol maleate $0.5 \%$ in subjects with open-angle glaucoma or ocular hypertension: the APOLLO Study. Ophthalmology. 20I6; I 23(5):965-973.68 Abbreviations: LBN, latanoprostene bunod; TEAEs, treatment-emergent adverse events.

versus 3.6\%), whereas conjunctival hyperemia was higher for LBN (3.3\% versus $0 \%$ ) after 3 months. ${ }^{54-57}$ In a large-scale trial involving latanoprost $(\mathrm{N}=411)$, the incidence of hyperemia was $47.1 \%$ after 3 months. ${ }^{77}$ Of note, the incidence of conjunctival hyperemia was higher (17.7\%) in the year-long JUPITER trial than in other trials of LBN.

The majority of hyperemia was mild in severity. However, the incidence of more profound and prolonged hyperemia with LBN may be greater compared to that associated with timolol. In APOLLO, the LBN group had a higher percentage of individuals with moderate-to-severe hyperemia compared to the group receiving timolol at all postbaseline time points (9.6\% versus $0.7 \%$ at week $2 ; 11.8 \%$ versus $3.8 \%$ at week 6 ; $8.5 \%$ versus $2.4 \%$ at month 3 ).

\section{Ocular irritation and pain}

Pain and irritation associated with LBN were characterized as either instillation site pain, eye irritation, or eye pain, with respective incidences of $8.3 \%, 1.7 \%$, and $1.1 \%$ across three pivotal studies. These adverse effects therefore have an approximate combined incidence of $11.1 \%$. However, this group of TEAEs are mostly mild and do not appear to affect tolerability. In APOLLO, only one subject in the LBN group discontinued therapy secondary to mild conjunctival irritation and edema, compared to one subject in the timolol group withdrawing secondary to moderate eye irritation. The year-long JUPITER trial noted greater incidences of discomfort-related effects (eye irritation, 11.5\%; eye pain, $10.0 \%$ ).

Instillation site pain occurred more frequently with LBN $(15.2 \%)$ versus latanoprost $(6.1 \%)$, but did not result in reduced adherence. Incidences of irritation and pain were similar between LBN and timolol.

\section{Dry eye and punctate keratitis}

Preserved eye drop formulations are known to impair ocular surface health, especially with prolonged use. ${ }^{78}$ A total of $3.0 \%$ of LBN-treated individuals from pooled study data demonstrated evidence of punctate keratitis on biomicroscopy. In VOYAGER, incidence with LBN (1.8\%) was similar to that with latanoprost (1.2\%). LBN was associated with a $0.9 \%$ incidence of dry eye in pooled data, which was higher than the incidence with latanoprost but comparable to that with timolol. 


\section{Iris and eyelid pigmentation}

Increased pigmentation of the iris and eyelid is the distinctive side effect of PGAs, although generally do not arise until after several months of treatment. As expected, therefore, these side effects were not observed in any shorter-term trials of LBN ( $\leq 3$ months), but were noted in the year-long JUPITER study. In this trial, $3.8 \%$ and $3.1 \%$ of individuals demonstrated iris hyperpigmentation and blepharal pigmentation, respectively. Other features of prostaglandin-associated periorbitopathy ${ }^{79}$ - such as blepharoptosis, deepening of the upper lid sulcus, and involution of dermatochalasis - have not been described with LBN.

\section{Hypertrichosis}

PGAs may induce eyelash growth. Only one study, JUPITER, has reported hypertrichosis as a TEAE of LBN, with $16.2 \%$ of individuals (21/103) experiencing eyelash growth. Although this may be a desirable cosmetic effect in some patients, it can present an aesthetic imbalance when occurring unilaterally, and in certain cases may interfere with eye drop administration. Further evaluation of the incidence and magnitude of this potential side effect of LBN - and its likelihood compared to that with other PGAs - may be warranted.

\section{Nonocular adverse events}

Nonocular and systemic side effects are rare with LBN, experienced by fewer than $1 \%$ of treated individuals (Table 3). The most common of these adverse events is headache, which is nonetheless exceedingly rare (3/637, $0.5 \%)$. There were no treatment-related changes in vital signs or any significant safety concerns associated with LBN in any study.

\section{Patient-focused perspectives}

Patients with vision loss from glaucoma, on average, report impaired quality of life. ${ }^{80,81}$ Profound disease and faster rate of visual field loss are also associated with poorer patient psychological outcomes. ${ }^{82}$ Accordingly, the need for effective treatment regimens that halt disease progression without further impairing the quality of life and overall well-being is paramount.

Assessments of patient satisfaction and acceptability with LBN, however, have not been reported in any clinical trial to date. However, PGAs may enhance certain aspects of patients' quality of life. For example, OAG and OHTN patients switching to latanoprost from other monotherapies report improved quality of life. ${ }^{83}$ This may be a function of the more favorable side-effect profiles and once-daily dosing regimen of PGAs compared to other ocular hypotensive medications.

Many barriers impede the delivery of effective medical treatment to individuals with OHTN or glaucoma, including eye drop intolerability, ${ }^{84-86}$ ineffectiveness of treatment, ${ }^{83}$ regimen complexity or inconvenience, ${ }^{84,86}$ and medication cost. ${ }^{84,87}$ Medication compliance - a manifestation of adherence and persistence - depends upon tolerability, convenience, and affordability.

The tolerability of LBN, as demonstrated by clinical trials, may promote patient compliance. Although risk and severity of some adverse reactions from LBN may be marginally increased compared to those of latanoprost, most of these reactions are nonetheless infrequent and mild and do not appear to reduce adherence. Furthermore, side effects of LBN are somewhat comparable to those of timolol, which, combined with LBN's markedly greater efficacy, may favor LBN as a first-line therapy. The potential risk for more severe hyperemia with LBN, however, is not insignificant. Hyperemia is a significant risk factor for patient noncompliance ${ }^{88}$ In cases of drug discontinuation related to side effects, hyperemia represented the most commonly cited reason, accounting for $65 \%{ }^{89}$

The potent effects of LBN as a monotherapy may promote tolerability and compliance. The use of monotherapy not only enhances convenience, ${ }^{90}$ but also likely reduces exposure to preservatives and risk of adverse effects compared with combination therapy. ${ }^{91}$ Complexity of eye drop regimen may also account for suboptimal compliance. Use of an effective monotherapy could minimize this barrier and discourage discontinuation.

Timing of dosing may be important in promoting compliance. Although many individuals find nightly dosing of PGAs practical and convenient, morning dosing schedules may be associated with improved adherence, particularly among males. ${ }^{92,93}$ LBN $0.024 \%$ dosed once nightly has demonstrated robust ocular hypotensive effects. The only published direct comparison of LBN $0.024 \%$ qAM versus qPM found no significant difference between the two at the primary end point. ${ }^{62,63}$ Timing of dose may be of importance, although complete head-to-head results comparing LBN $0.024 \%$ qAM versus qPM have not been published. These results may have significant implications on efficacy and patient compliance. A direct, rigorous comparison of the two may therefore be of clinical relevance.

\section{Conclusion}

Multiple preclinical and clinical studies underscore the efficacy, safety, and tolerability of LBN as an ocular 
hypotensive agent. The profound IOP-lowering effects of LBN monotherapy have been consistent and reproducible across trials, surpassing those of latanoprost or timolol monotherapy. Targeting of both the uveoscleral and conventional aqueous outflow pathways may account for LBN's robust therapeutic activity.

Clinical trials demonstrate that LBN can offer, on average, approximately $1-3 \mathrm{mmHg}$ additional improvement over latanoprost and timolol. This is not insignificant, as data from the Ocular Hypertension Treatment Study and Early Manifest Glaucoma Trial indicate that each $\mathrm{mmHg}$ reduction in IOP from baseline reduces the risk of onset or progression of glaucoma in eyes with elevated IOP. ${ }^{94,95}$

LBN $0.024 \%$ once daily has been demonstrated as an optimal dosing regimen, with superior ocular hypotensive effect and comparable risk of adverse events to other concentrations. This dose has demonstrated profound IOP reductions both in mean diurnal, nocturnal, and 24-hour IOP as well as across multiple time points throughout the day.

LBN may have marginally increased risk of ocular adverse reactions compared to latanoprost, although the overwhelming majority are transient and mild. Longer-term treatment with LBN may result in increased risk of development of ocular side effects such as eye-related irritation and pain. Despite this, LBN has been associated with high tolerability and compliance.

$\mathrm{LBN}$ is an effective pharmacologic agent emerging from the developmental pipeline for controlling IOP in OAG and OHTN. The promising results of LBN to date warrant further clinical evaluation, particularly in individuals with normaltension glaucoma. LBN may be an effective therapeutic tool in the ophthalmologist's arsenal to combat visual disability and improve patients' quality of life.

\section{Acknowledgments}

The author KYL would like to thank Professor John P. Cooke at Stanford University for introducing him to the fascinating world of vascular biology and nitric oxide, which partly inspired the present article. The Department of Ophthalmology at University of California, Irvine, is a recipient of an institutional Research to Prevent Blindness unrestricted grant.

\section{Disclosure}

The authors report no conflicts of interest in this work.

\section{References}

1. Charlson ME, de Moraes CG, Link A, et al. Nocturnal systemic hypotension increases the risk of glaucoma progression. Ophthalmology. 2014;121:2004-2012.
2. Kamal D, Hitchings R. Normal tension glaucoma - a practical approach. Br J Ophthalmol. 1998;82(7):835-840.

3. Lee AJ, McCluskey P. Clinical utility and differential effects of prostaglandin analogs in the management of raised intraocular pressure and ocular hypertension. Clin Ophthalmol. 2010;4:741-764.

4. Schwartz GF, Quigley HA. Adherence and persistence with glaucoma therapy. Surv Ophthalmol. 2008;53(Suppl 1):S57-S68.

5. Nordstrom BL, Friedman DS, Mozaffari E, Quigley HA, Walker AM. Persistence and adherence with topical glaucoma therapy. Am J Ophthalmol. 2005;140(4):598-606.

6. Spooner JJ, Bullano MF, Ikeda LI, et al. Rates of discontinuation and change of glaucoma therapy in a managed care setting. Am J Manag Care. 2002;8:S262-S270.

7. Patel SC, Spaeth GL. Compliance in patients prescribed eyedrops for glaucoma. Ophthalmic Surg. 1995;26:233-236.

8. Campbell JH, Schwartz GF, LaBounty B, Kowalski JW, Patel VD. Patient adherence and persistence with topical ocular hypotensive therapy in real-world practice: a comparison of bimatoprost $0.01 \%$ and travoprost Z 0.004\% ophthalmic solutions. Clin Ophthalmol. 2014;8: 927-935.

9. Krauss AH, Impagnatiello F, Toris CB, et al. Ocular hypotensive activity of BOL-303259-X, a nitric oxide donating prostaglandin $\mathrm{F}_{2 \alpha}$ agonist, in preclinical models. Exp Eye Res. 2011;93(3):250-255.

10. Stamer WD, Acott TS. Current understanding of conventional outflow dysfunction in glaucoma. Curr Opin Ophthalmol. 2012;23(2): $135-143$.

11. Sharif NA, Kelly CR, Crider JY. Agonist activity of bimatoprost, travoprost, latanoprost, unoprostone isopropyl ester and other prostaglandin analogs at the cloned human ciliary body FP prostaglandin receptor. J Ocul Pharmacol Ther. 2002;18(4):313-324.

12. Schlotzer-Schrehardt U, Zenkel M, Nüsing RM. Expression and localization of FP and EP prostanoid receptor subtypes in human ocular tissues. Invest Ophthalmol Vis Sci. 2002;43(5):1475-1487.

13. Weinreb RN, Lindsey JD. Metalloproteinase gene transcription in human ciliary muscle cells with latanoprost. Invest Ophthalmol Vis Sci. 2002;43(3):716-722.

14. Sagara T, Gaton DD, Lindsey JD, Gabelt BT, Kaufman PL, Weinreb RN. Topical prostaglandin $\mathrm{F}_{2 \alpha}$ treatment reduces collagen types I, III, and IV in the monkey uveoscleral outflow pathway. Arch Ophthalmol. 1999; 117:794-801.

15. Ocklind A. Effect of latanoprost on the extracellular matrix of the ciliary muscle. A study on cultured cells and tissue sections. Exp Eye Res. 1998;67(2):179-191.

16. Weinreb RN, Kashiwagi K, Kashiwagi F, Tsukahara S, Lindsey JD. Prostaglandins increase matrix metalloproteinase release from human ciliary smooth muscle cells. Invest Ophthalmol Vis Sci. 1997;38(13): 2772-2780.

17. Weinreb RN, Lindsey JD, Marchenko G, Marchenko N, Angert M, Strongin A. Prostaglandin FP agonists alter metalloproteinase gene expression in sclera. Invest Ophthalmol Vis Sci. 2004;45(12): 4368-4377.

18. Anthony TL, Lindsey JD, Weinreb RN. Latanoprost's effects on TIMP-1 and TIMP-2 expression in human ciliary muscle cells. Invest Ophthalmol Vis Sci. 2002;43(12):3705-3711.

19. Kim JW, Lindsey JD, Wang N, Weinreb RN. Increased human scleral permeability with prostaglandin exposure. Invest Ophthalmol Vis Sci. 2001;42(7):1514-1521.

20. Stjernschantz J, Selén G, Ocklind A, Resul B. Effects of latanoprost and related prostaglandin analogues. In: Alm A, Weinreb RN, editors. Uveoscleral Outflow: Biology and Clinical Aspects. London, UK: Mosby International Limited; 1998:57-72.

21. Toris CB, Gabelt BT, Kaufman PL. Update on the mechanism of action of topical prostaglandins for intraocular pressure reduction. Surv Ophthalmol. 2008;53(Suppl 1):S107-S120.

22. Lim KS, Nau CB, O’Byrne MM, et al. Mechanism of action of bimatoprost, latanoprost, and travoprost in healthy subjects. A crossover study. Ophthalmology. 2008;115(5):790-795.e4. 
23. Hinz B, Rösch S, Ramer R, Tamm ER, Brune K. Latanoprost induces matrix metalloproteinase-1 expression in human nonpigmented ciliary epithelial cells through a cyclooxygenase-2-dependent mechanism. FASEB J. 2005;19(13):1929-1931.

24. Stamer WD, Lei Y, Boussommier-Calleja A, Overby DR, Ethier CR. eNOS, a pressure-dependent regulator of intraocular pressure. Invest Ophthalmol Vis Sci. 2011;52(13):9438-9444.

25. Kotikoski H, Alajuuma P, Moilanen E, et al. Comparison of nitric oxide donors in lowering intraocular pressure in rabbits: role of cyclic GMP. J Ocul Pharmacol Ther. 2002;18(1):11-23.

26. Chuman H, Chuman T, Nao-i N, Sawada A. The effect of L-arginine on intraocular pressure in the human eye. Curr Eye Res. 2000;20(6): 511-516.

27. Schuman JS, Erickson K, Nathanson JA. Nitrovasodilator effects on intraocular pressure and outflow facility in monkeys. Exp Eye Res. 1994; 58(1):99-105.

28. Nathanson JA. Nitrovasodilators as a new class of ocular hypotensive agents. J Pharmacol Exp Ther. 1992;260(3):956-965.

29. Wizemann AJ, Wizemann V. Organic nitrate therapy in glaucoma. Am J Ophthalmol. 1980;90(1):106-109.

30. Arnal JF, Dinh-Xuan AT, Pueyo M, Darblade B, Rami J. Endotheliumderived nitric oxide and vascular physiology and pathology. Cell Mol Life Sci. 1999;55:1078-1087.

31. Dismuke WM, Mbadugha CC, Ellis DZ. NO-induced regulation of human trabecular meshwork cell volume and aqueous humor outflow facility involve the BKCa ion channel. Am J Physiol Cell Physiol. 2008; 294:C1378-C1386.

32. Ellis DZ, Dismuke WM, Chokshi BM. Characterization of soluble guanylate cyclase in NO-induced increases in aqueous humor outflow facility and in the trabecular meshwork. Invest Ophthalmol Vis Sci. 2009; 50(4):1808-1813.

33. Dismuke WM, Liang J, Overby DR, Stamer WD. Concentration-related effects of nitric oxide and endothelin-1 on human trabecular meshwork cell contractility. Exp Eye Res. 2014;120:28-35.

34. Rao PV, Deng P, Sasaki Y, Epstein DL. Regulation of myosin light chain phosphorylation in the trabecular meshwork: role in aqueous humour outflow facility. Exp Eye Res. 2005;80(2):197-206.

35. Schneemann A, Dijkstra BG, van den Berg TJ, Kamphuis W, Hoyng PF. Nitric oxide/guanylate cyclase pathways and flow in anterior segment perfusion. Graefes Arch Clin Exp Ophthalmol. 2002;240(11):936-941.

36. Ellis DZ, Sharif NA, Dismuke WM. Endogenous regulation of human Schlemm's canal cell volume by nitric oxide signaling. Invest Ophthalmol Vis Sci. 2010;51(11):5817-5824.

37. Heimark RL, Kaochar S, Stamer WD. Human Schlemm's canal cells express the endothelial adherens proteins, VE-cadherin and PECAM-1. Curr Eye Res. 2002;25(5):299-308.

38. de Kater AW, Spurr-Michaud SJ, Gipson IK. Localization of smooth muscle myosin-containing cells in the aqueous outflow pathway. Invest Ophthalmol Vis Sci. 1990;31(2):347-353.

39. Krupin T, Weiss A, Becker B, Holmberg N, Fritz C. Increased intraocular pressure following topical azide or niroprusside. Invest Ophthalmol Vis Sci. 1977;16(11):1002-1007.

40. Zamora DO, Kiel JW. Episcleral venous pressure responses to topical nitroprusside and N-Nitro-L-arginine methyl ester. Invest Ophthalmol Vis Sci. 2010;51(3):1614-1620.

41. Funk RH, Gehr J, Rohen JW. Short-term hemodynamic changes in episcleral arteriovenous anastomoses correlate with venous pressure and IOP changes in the albino rabbit. Curr Eye Res. 1996;15(1):87-93.

42. Saeki T, Tsuruga H, Aihara M, Araie M, Rittenhouse K. Dose-response profile of PF-03187207 (PF-207) and peak IOP lowering response following single topical administration to FP receptor knockout mice vs wild type mice. Invest Ophthalmol Vis Sci. 2009;50(13):ARVO E-Abstract 4064.

43. Krauss AH, Toris CA, Kallberg ME, et al. Ocular hypotensive activity of PF-03187207, a nitric oxide donating prostaglandin analog, in preclinical models. Invest Ophthalmol Vis Sci. 2009;50:ARVO E-Abstract 1471.
44. Cavet ME, Vollmer TR, Harrington K, VanDerMeid K, Richardson M. NO-induced regulation of primary human trabecular meshwork cell contractility by latanoprostene bunod. Invest Ophthalmol Vis Sci. 2014; 55(13):ARVO E-Abstract 546.

45. Cavet ME, Vollmer TR, Harrington KL, VanDerMeid K, Richardson ME. Regulation of endothelin-1-induced trabecular meshwork cell contractility by latanoprostene bunod. Invest Ophthalmol Vis Sci. 2015; 56(6):4108-4116.

46. Sjöquist B, Stjernschantz J. Ocular and systemic pharmacokinetics of latanoprost in humans. Surv Ophthalmol. 2002;47(Suppl 1): S6-S12.

47. Resul B, Stjernschantz J, Selén G, Bito L. Structure-activity relationships and receptor profiles of some ocular hypotensive prostanoids. Surv Ophthalmol. 1997;41(Supp1 2):S47-S52.

48. Stjernschantz K, Selén G, Sjöquist B, Resul B. Preclinical pharmacology of latanoprost, a phenyl-substituted PGF2 alpha analogue. Adv Prostaglandin Thromboxane Leukot Res. 1995;23:513-518.

49. Orihashi M, Shima Y, Tsuneki H, Kimura I. Potent reduction of intraocular pressure by nipradilol plus latanoprost in ocular hypertensive rabbits. Biol Pharm Bull. 2005;28(1):65-68.

50. Woodward DF, Burke JA, Williams LS, et al. Prostaglandin F2 alpha effects on intraocular pressure negatively correlate with FP-receptor stimulation. Invest Ophthalmol Vis Sci. 1989;30(8): 1838-1842.

51. Araie M, Sforzolini BS, Vittitow J, Weinreb RN. Evaluation of the effect of latanoprostene bunod ophthalmic solution, $0.024 \%$ in lowering intraocular pressure over $24 \mathrm{~h}$ in healthy Japanese subjects. Adv Ther. 2015;32(11):1128-1139.

52. Araie M, Scassellati-Sforzolini B, Ngumah Q, Vittitow J, Weinreb R. Efficacy of Vesneo ${ }^{\mathrm{TM}}$ (Latanoprostene bunod ophthalmic solution, $0.024 \%$ ) in Lowering Intraocular Pressure Over 24 hours in Healthy Japanese Subjects. Poster presented at: 6th World Glaucoma Congress; June 6-9; 2015; Hong Kong, China: Abstract P-S-056.

53. Araie M, Ong T, Scassellati-Sforzolini B, Ngumah Q, Vittitow JL, Weinreb RN. Efficacy of latanoprostene bunod ophthalmic solution, $0.024 \%$, in lowering intraocular pressure over 24-hours in normal Japanese subjects (KRONUS). Invest Ophthalmol Vis Sci. 2014;55(13): ARVO E-Abstract 548

54. Weinreb RN, Ong T, Scassellati Sforzolini B, et al. A randomised, controlled comparison of latanoprostene bunod and latanoprost $0.005 \%$ in the treatment of ocular hypertension and open angle glaucoma: the VOYAGER study. Br J Ophthalmol. 2015;99(6):738-745.

55. Weinreb RN, Ong T, Scassellati B, et al. A prospective randomized, multicenter, single-masked, parallel, dose ranging (VOYAGER) study to compare the safety and efficacy of BOL-303259-X to latanoprost in subjects with open-angle glaucoma or ocular hypertension. Paper presented at: 23rd Annual Meeting of the American Glaucoma Society; 2013; Vancouver, Canada.

56. Weinreb RN. A prospective randomized, multicenter, single-masked, parallel, dose ranging (VOYAGER) study to compare the safety and efficacy of BOL-303259-X to latanoprost in subjects with open-angle glaucoma or ocular hypertension. 2013. World Glaucoma Congress. Paper presentation.

57. Katz LJ, Kaufman P, Ong T, Scassellati-Sforzolini B, Vittitow J. Latanoprostene bunod $0.024 \%$ significantly reduces and maintains mean diurnal intra-ocular pressure (IOP) compared to latanoprost $0.005 \%$ in subjects with open angle glaucoma or ocular hypertension. Invest Ophthalmol Vis Sci. 2013;54(13):ARVO E-Abstract 460.

58. Iwase A, Suzuki Y, Araie M, et al. The prevalence of primary openangle glaucoma in Japanese: the Tajimi Study. Ophthalmology. 2004; 111(9):1641-1648.

59. Quaranta L, Katsanos A, Russo A, Riva I. 24-hour intraocular pressure and ocular perfusion pressure in glaucoma. Surv Ophthalmol. 2013; 58(1):26-41.

60. Deokule S, Weinreb RN. Relationships among systemic blood pressure, intraocular pressure, and open-angle glaucoma. Can J Ophthalmol. 2008;43(3):302-307. 
61. Nickens D, Mandema J, Courtney R, Raber S, Bosworth C. A modelbased dose-response meta-analysis of single agent intraocular pressure (IOP) therapies used to evaluate efficacy of a potential new therapy (PF-03187207) in glaucoma patients. Invest Ophthalmol Vis Sci. 2009; 50(13):ARVO E-Abstract 2479.

62. Bosworth CF, Zhang M, Courtney R, Raber S, Eveleth D, Beekman M. Efficacy and safety of PF-03187207, a novel nitric oxide donating prostaglandin F2-alpha analogue, vs latanoprost in hypertensive eyes. Invest Ophthalmol Vis Sci. 2009;50(13):ARVO E-Abstract 2481.

63. Raber S, Zhang M, Courtney R, Eveleth D. Comparison of once-daily morning or evening dosing of PF-03187207, a novel nitric oxide donating prostaglandin $\mathrm{f} 2$-alpha analogue, vs latanoprost in hypertensive eyes. Florence, Italy: European Glaucoma Society; 2010;Abstract P3.1.

64. Liu JHK, Vittitow JL, Ngumah Q, Weinreb RN. Efficacy of Latanoprostene bunod ophthalmic solution $0.024 \%$ compared with timolol maleate ophthalmic solution $0.5 \%$ in lowering IOP over 24 hours in Subjects with open angle glaucoma or ocular hypertension (CONSTELLATION). Invest Ophthalmol Vis Sci. 2014;55(13):ARVO E-Abstract.

65. Liu J, Vittitow J, Sforzolini B, Weinreb R. Effects of latanoprostene bunod compared with timolol maleate on ocular perfusion pressure in subjects with open-angle glaucoma or ocular hypertension. 2015. American Glaucoma Society. Abstract PO015.

66. Scassellati Sforzolini B, Vittitow J, Weinreb R. Efficacy of Vesneo ${ }^{\mathrm{TM}}$ (latanoprostene bunod ophthalmic solution, 0.024\%) compared with timolol maleate ophthalmic solution $0.5 \%$ in subjects with open-angle glaucoma or ocular hypertension. 2015. World Glaucoma Congress. Abstract RF-T-03-07.

67. Liu J, Vittitow J, Scassellati Sforzolini B, Weinreb R. Ocular perfusion pressure effects of Vesneo ${ }^{\mathrm{TM}}$ (latanoprostene bunod ophthalmic solution, $0.024 \%$ ) timolol maleate ophthalmic solution $0.5 \%$ in subjects with open-angle glaucoma or ocular hypertension. 2015. World Glaucoma Congress. Abstract P-S-074.

68. Weinreb RN, Scassellati Sforzolini B, Vittitow J, Liebmann J. Latanoprostene bunod $0.024 \%$ versus timolol maleate $0.5 \%$ in subjects with open-angle glaucoma or ocular hypertension: the APOLLO Study. Ophthalmology. 2016;123(5):965-973.

69. Vittitow J, Liebmann JM, Weinreb R. The effect of latanoprostene bunod $0.024 \%$ vs timolol maleate $0.5 \%$ on lowering intraocular pressure in patients with open-angle glaucoma or ocular hypertension: the APOLLO Study. 2016. American Glaucoma Society. Abstract PO086.

70. Vittitow JL, Liebmann JM, Kaufman PL, Medeiros FA, Martin KR, Weinreb RN. Long-term efficacy and safety of latanoprostene bunod $0.024 \%$ for intraocular pressure lowering in patients with open-angle glaucoma or ocular hypertension: APOLLO and LUNAR studies. Invest Ophthalmol Vis Sci. 2016;57:ARVO E-Abstract 3030.

71. Kaufman PL, Liebmann JM, Vittitow JL, Weinreb RN. Integrated efficacy of latanoprostene bunod $0.024 \%$ vs timolol maleate $0.5 \%$ for intraocular pressure lowering in patients with open-angle glaucoma or ocular hypertension: APOLLO and LUNAR studies. Invest Ophthalmol Vis Sci. 2016;57:ARVO E-Abstract 3036.

72. Medeiros FA, Martin KR, Peace J, Scassellati Sforzolini B, Vittitow JL, Weinreb RN. Comparison of Latanoprostene Bunod $0.024 \%$ and Timolol Maleate $0.5 \%$ in Open-Angle Glaucoma or Ocular Hypertension: the LUNAR Study. Am J Ophthalmol. Epub 2016 May 19.

73. Peace JH, Medeiros FA, Martin KR, Vittitow JL, Weinreb RN. Efficacy of latanoprostene bunod $0.024 \%$ vs timolol maleate $0.5 \%$ for intraocular pressure lowering in patients with open angle glaucoma or ocular hypertension: the LUNAR study. Invest Ophthalmol Vis Sci. 2016;57: ARVO E-Abstract 3035.

74. Kawase K, Vittitow JL, Yamamoto T, Araie M. Long-term safety and intraocular pressure lowering efficacy of latanoprostene bunod $0.024 \%$ in Japanese subjects with open angle glaucoma or ocular hypertension: the JUPITER study. Invest Ophthalmol Vis Sci. 2016;57:ARVO E-Abstract 3037

75. Henry JC, Peace JH, Stewart JA, Stewart WC. Efficacy, safety, and improved tolerability of travoprost BAK-free ophthalmic solution compared with prior prostaglandin therapy. Clin Ophthalmol. 2008;2:613-621.
76. Guenoun JM, Baudouin C, Rat P, Pauly A, Warnet JM, Brignole-Baudouin $\mathrm{F}$. In vitro study of inflammatory potential and toxicity profile of latanoprost, travoprost, and bimatoprost in conjunctiva-derived epithelial cells. Invest Ophthalmol Vis Sci. 2005;46: 2444-2450.

77. Parrish RK, Palmberg P, Sheu WP; XLT Study Group. A comparison of latanoprost, bimatoprost, and travoprost in patients with elevated intraocular pressure: a 12-week, randomized, masked-evaluator multicenter study. Am J Ophthalmol. 2003;135(5):688-703.

78. Baudouin C. Detrimental effect of preservatives in eyedrops: implications for the treatment of glaucoma. Acta Ophthalmol. 2008;86(7): 716-726.

79. Berke SJ. PAP: New concerns for prostaglandin use. Rev Ophthalmol. 2012;19(10):70.

80. Nelson P, Aspinall P, Papasouliotis O, Worton B, O’Brien C. Quality of life in glaucoma and its relationship with visual function. J Glaucoma. 2003;12(2):139-150.

81. Skalicky S, Goldberg I. Depression and quality of life in patients with glaucoma: a cross-sectional analysis using the Geriatric Depression Scale-15, assessment of function related to vision, and the Glaucoma Quality of Life-15. J Glaucoma. 2008;17(7):546-551.

82. Diniz-Filho A, Abe RY, Cho HJ, Baig S, Gracitelli CP, Medeiros FA. Fast visual field progression Is associated with depressive symptoms in patients with glaucoma. Ophthalmology. 2016;123(4):754-759.

83. Zimmerman TJ, Stewart WC; Latanoprost Axis Study Group. Intraocular pressure, safety, and quality of life in glaucoma patients switching to latanoprost from monotherapy treatments. J Ocul Pharmacol Ther. 2003;19(5):405-415.

84. Stryker JE, Beck AD, Primo SA, et al. An exploratory study of factors influencing glaucoma treatment adherence. J Glaucoma. 2010;19(1): $66-72$.

85. Tsai JC, McClure CA, Ramos SE, Schlundt DG, Pichert JW. Compliance barriers in glaucoma: a systematic classification. J Glaucoma. 2003;12(5):393-398.

86. Taylor SA, Galbraith SM, Mills RP. Causes of non-compliance with drug regimens in glaucoma patients: a qualitative study. $J$ Ocul Pharmacol Ther. 2002;18(5):401-409.

87. Lacey J, Cate H, Broadway DC. Barriers to adherence with glaucoma medications: a qualitative research study. Eye (Lond). 2009;23(4): 924-932.

88. Friedman DS, Hahn SR, Gelb L, et al. Doctor-patient communication, health-related beliefs, and adherence in glaucoma results from the glaucoma adherence and persistency Study (GAPS). Ophthalmology. 2008;115(8):1320-1327.

89. Feldman RM. Conjunctival hyperemia and the use of topical prostaglandins in glaucoma and ocular hypertension. JOcul Pharmacol Ther. 2003;19(1):23-35.

90. Abelson MB, Netland PA, Chapin MJ. Switching patients with glaucoma or ocular hypertension from dual therapy to monotherapy: evaluation of brimonidine as a model. Adv Ther. 2001;18(6):282-297.

91. Pisella PJ, Pouliquen P, Baudouin C. Prevalence of ocular symptoms and signs with preserved and preservative free glaucoma medication. Br J Ophthalmol. 2002;86:418-423.

92. Kahook MY, Noecker RJ. Evaluation of adherence to morning versus evening glaucoma medication dosing regimens. Clin Ophthalmol. 2007;1(1):79-83.

93. Ford BA, Gooi M, Carlsson A, Crichton AC. Morning dosing of oncedaily glaucoma medication is more convenient and may lead to greater adherence than evening dosing. J Glaucoma. 2013;22(1):1-4.

94. Kass MA, Heuer DK, Higginbotham EJ, et al. The Ocular Hypertension Treatment Study: a randomized trial determines that topical ocular hypotensive medication delays or prevents the onset of primary openangle glaucoma. Arch Ophthalmol. 2002;120(6):701-713; discussion 829-830.

95. Leske MC, Heijl A, Hussein M, et al. Factors for glaucoma progression and the effect of treatment: the early manifest glaucoma trial. Arch Ophthalmol. 2003;121:48-56. 


\section{Publish your work in this journal}

Clinical Ophthalmology is an international, peer-reviewed journal covering all subspecialties within ophthalmology. Key topics include: Optometry; Visual science; Pharmacology and drug therapy in eye diseases; Basic Sciences; Primary and Secondary eye care; Patient Safety and Quality of Care Improvements. This journal is indexed on

Submit your manuscript here: http://www.dovepress.com/clinical-ophthalmology-journal
PubMed Central and CAS, and is the official journal of The Society of Clinical Ophthalmology (SCO). The manuscript management system is completely online and includes a very quick and fair peer-review system, which is all easy to use. Visit http://www.dovepress.com/ testimonials.php to read real quotes from published authors. 